
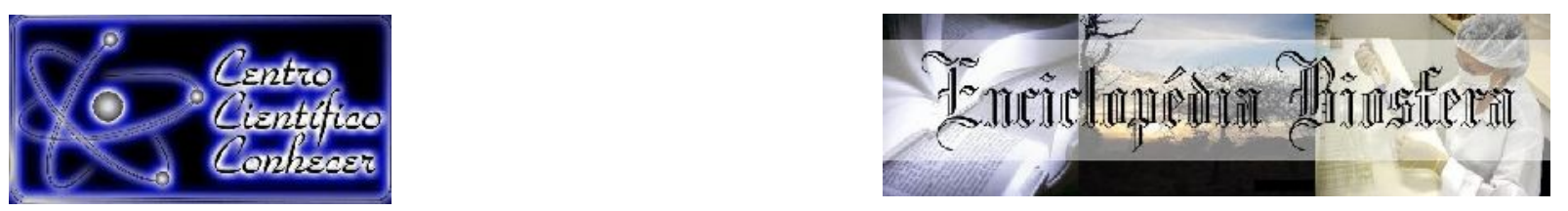

\title{
PATÓGENOS DE SOLO: PRINCIPAIS DOENÇAS VASCULARES E RADICULARES E FORMAS DE CONTROLE
}

\section{Rafael Barbieri Bellé ${ }^{1}$, Daniele Cristina Fontana ${ }^{2}$}

${ }_{1}^{1}$ Acadêmico em Engenharia Agronômica pela Universidade Federal de Santa Maria, campus Frederico Westphalen, Departamento de Ciências Agronômicas e Ambientais. Frederico Westphalen, RS, Brasil.

2 Doutoranda em Fitotecnia pela Universidade de São Paulo, Escola Superior de Agricultura Luiz de Queiroz, Departamento de Produção Vegetal. Piracicaba, SP, Brasil, daani_fontana@usp.br

Recebido em: 22/09/2018 - Aprovado em: 23/11/2018 - Publicado em: 03/12/2018 DOI: 10.18677/EnciBio_2018B65

\begin{abstract}
RESUMO
O solo não é um meio de cultivo totalmente inerte, apresenta em sua composição fungos, bactérias e microrganismos que compõem a microbiota do solo. A agricultura moderna e a utilização frequente do solo auxiliaram no desequilíbrio biológico, aumentando a população de determinados microrganismos (tornando-os patogênicos) e reduzindo a de outros. Dessa forma, o controle de patógenos de solo tem se tornado difícil, e os fungicidas comumente utilizados não apresentam espectro de ação eficiente sobre o solo. Dessa forma, o objetivo deste trabalho foi apresentar os principais causadores de doenças vasculares e radiculares e formas de controle recomendadas. Os microrganismos estudados foram Verticillium, Sclerotium rolfsii, Macrophomina phaseolina, Rhizoctonia, Pythium sp., Phytophthora, Fusarium sp., Scleriotinia sclerotiorum, Ralstonia, Meloidogyne, Pratylenchus, Heterodera glycines e Dytilenchus dipsaci. Diante dos mecanismos de patogenicidade e da especificidade de cada microrganismo, as formas mais comuns de controle recomendadas para estas epidemias são a rotação de culturas, uso de cultivares resistentes, controle físico, controle biológico, controle químico, controle cultural, utilizando o manejo integrado de doenças. Cada patossistema apresenta características intrínsecas e que modificam o manejo de controle da doença. Contudo, de modo geral, para a eficiência de controle é recomendável que sejam realizadas todas as medidas indicadas, priorizando o manejo integrado de doenças, a manutenção do equilíbrio ecológico e a redução da contaminação ambiental.
\end{abstract}

PALAVRAS-CHAVE: epidemias, murcha, tombamento de plântulas. 


\title{
SOIL PATHOGENS: A REVIEW THAT PRESENTS THE MAIN CAUSES OF VASCULAR AND RADICAL DISEASES AND FORMS OF CONTROL
}

\begin{abstract}
Analyzing soil as a living ecosystem means analyzing various changes in the way it is cared for. Soil is not a totally inert culture medium, it has in its composition fungi, bacteria and microorganisms that make up the soil microbiota. Modern agriculture and frequent land use have promoted biological imbalance, increasing the population of certain micro-organisms (making them pathogenic) and reducing that of others. Thus, the control of soil pathogens has become difficult, and the commonly used fungicides do not present an efficient action spectrum on the soil. Thus, the objective of this work was to present the main causes of vascular and root diseases and recommended forms of control. The microorganisms studied were Verticillium, Sclerotium rolfsii, Macrophomina phaseolina, Rhizoctonia, Pythium sp., Phytophthora, Fusarium sp., Scleriotinia sclerotiorum, Ralstonia, Meloidogyne, Pratylenchus, Heterodera glycines and Dytilenchus dipsaci. Considering the mechanisms of pathogenicity and specificity of each microorganism, the most common forms of control recommended for these epidemics are crop rotation, use of resistant cultivars, physical control, biological control, chemical control, cultural control, using integrated management of diseases. Each pathosystem has intrinsic characteristics that modify the management of disease control. However, in general, for control efficiency it is recommended that all the indicated measures be carried out, prioritizing the integrated management of diseases, maintaining ecological balance and environmental contamination.
\end{abstract}

KEYWORDS: epidemics, wilt, seedling tipping.

\section{INTRODUÇÃO}

A qualidade do solo representa a capacidade de um solo funcionar dentro dos limites de um ecossistema natural ou manejado, para sustentar a produtividade de plantas e animais, manter ou aumentar a qualidade do ar, da água, e promover a saúde das plantas, dos animais e do homem (MCBRATNEY et al., 2014). Em outras palavras, é a capacidade do solo exercer suas funções na natureza que são: funcionar como meio para crescimento das plantas, regular e compartimentalizar o fluxo de água no ambiente, estocar e promover a ciclagem dos elementos da atmosfera, e servir como tampão ambiental na formação, atenuação e degradação de compostos prejudiciais ao meio ambiente (MCBRATNEY et al., 2014). Segundo este mesmo autor, o solo desempenha papel fundamental, pois é responsável pela sustentabilidade ambiental e da segurança alimentar, segurança hídrica, energética, estabilidade climática, biodiversidade e prestação de serviços ecossistêmicos, por isso as decisões tomadas devem ser adequadas tanto a nível regional quanto local, a fim de preservar as funções do solo.

Em ecossistemas agrícolas, a remoção da vegetação natural para a introdução sequencial de espécies vegetais de alta produtividade, é responsável por mudanças significativas na estrutura da comunidade microbiana do solo. Acredita-se que a redução da diversidade microbiana dos solos esteja acompanhada da redução da diversidade de plantas cultivadas e dos insumos utilizados, prejudicando importantes funções ecológicas (MASSENSSINI et al., 2015). A partir deste desequilíbrio, surgem

ENCICLOPÉDIA BIOSFERA, Centro Científico Conhecer - Goiânia, v.15 n.28; p.780 2018 
populações frequentes de alguns microrganismos, aumentando sua densidade populacional e tornando-se patogênico à culturas de interesse. Neste mesmo sentido, a agricultura convencional tem contribuído positivamente para o aumento populacional de microrganismos patogênicos, promovendo a ocorrência de problemas como, por exemplo, doenças radiculares e vasculares (VAN BRUGGEN; SEMENOV 2015).

As doenças de solo podem levar a reduções significativas no rendimento de várias culturas (VAN BRUGGEN; FINCKH, 2016), como é o caso de Fusarium sp., agente da podridão da raiz acometendo culturas como o Phaseolus vulgaris (NASERI; HAMADANI, 2017) e Beta vulgaris (FREDDO et al., 2016), e da Scleriotinia sclerotiorum agente causal do mofo branco em lavouras de soja (FURLAN, 2015) e outras, sendo o foco nesta revisão apresentar os principais patógenos de solo e suas formas de controle.

\section{DESENVOLVIMENTO}

As doenças radiculares e vasculares estão entre as principais causas de redução na produtividade de culturas de interesse alimentar mundial. Em cultivos tropicais, essas doenças têm recebido pouca atenção quando comparado às doenças foliares, principalmente quando os sintomas são confinados às raízes. Dentre os organismos causadores de doenças radiculares destacam-se os fungos, as bactérias e os nematóides, denominados generalizadamente como patógenos radiculares ou fitopatógenos habitantes do solo. O controle de doenças radiculares é muito difícil, pois os patógenos coevoluiram com as plantas por milhões de anos e estão altamente adaptados ao ambiente subterrâneo em associação com o hospedeiro (MICHEREFF et al., 2005).

Os fungos constituem o maior grupo de patógenos radiculares, ocorrendo em todos os tipos de sistemas agrícolas e causando doenças nas principais espécies cultivadas, com uma variada gama de sintomas. Muitos fungos habitantes do solo possuem elevada capacidade de competição saprofítica e podem sobreviver em resíduos de plantas introduzidos no solo, mantendo-se em elevadas densidades populacionais mesmo durante longos períodos de rotação de culturas. Outros fungos que vivem nesse ambiente produzem estruturas como agregados miceliais, esclerócios, oósporos, clamidosporos ou outros tipos de esporos, que resistem às condições ambientais adversas e permanecem viáveis quando as plantas hospedeiras não estão presentes. Essas estruturas podem estar associadas com resíduos de plantas, mas freqüentemente encontram-se livres no solo. Esse conjunto de características é uma das razões pela qual fungos fitopatogênicos habitantes do solo, uma vez introduzidos numa área de plantio, são praticamente impossíveis de serem eliminados (WHEELER; RUSH, 2001).

A agricultura, além do fornecimento de alimentos para a população, apresenta grande importância na geração de empregos e renda, sendo por tanto, uma das principais atividades econômicas do Brasil e do mundo. Dada à importância da agricultura, o solo constitui um dos mais importantes recursos para produção de alimentos. Para que o potencial produtivo de solo seja preservado, faz-se necessário a adoção de práticas de manejo que permitam menor incidência de doenças, e se elas incidirem, que as medidas de controle sejam eficientes. Dessa forma, torna-se importante conhecer um pouco sobre os principais patógenos de solo e sua biologia, 
bem como as medidas controles recomendados solo.

\section{PATÓGENOS DE SOLO CAUSADORES DE DOENÇAS}

\section{1) Murcha de Verticillium (murcha verticilar)}

Fungos do gênero Verticillium são altamente destrutivos e causadores de murcha vascular, causando severas perdas na produção e qualidade de diferentes culturas economicamente importantes, além de apresentar distribuição mundial (DAAYF, 2015). Os isolados apresentam grande plasticidade na virulência e especificidade do hospedeiro, e seu impacto, geralmente é prejudicial tanto para o rendimento econômico quanto para a qualidade do uso final (ATALLAH et al., 2011). Além disso, as condições climáticas são desfavoráveis ao desenvolvimento da doença, que é mais severa em temperaturas que variam de $18-22^{\circ} \mathrm{C}$. No entanto, essa doença é muito importante nos EUA, México, Peru, Rússia, Argentina e Índia. O desenvolvimento dessa doença é favorecido por temperaturas entre 18 e $22^{\circ} \mathrm{C}$. Sua disseminação é realizada por sementes contaminadas, vento, água superficial e pelo próprio solo contaminado (BACCHI et al., 2001).

Esses patógenos transmitidos pelo solo colonizam a raiz da planta em resposta a exsudatos radiculares a qualquer momento durante o cultivo, penetram no córtex e endoderme e se disseminam sistemicamente através de conídios transportados pela corrente de transpiração no xilema (ZHAO et al., 2014). Os sintomas são verificados em reboleira e incluem baixa estatura das plantas, clorose e murchamento das plantas hospedeiras durante 0 desenvolvimento da doença, justamente pelo seu desenvolvimento no xilema das plantas (KLOSTERMAN et al., 2011).

Acometem culturas como o morangueiro (SOWIK et al., 2016), tomateiro (MIRANDA et al., 2010), berinjela (CORDER; MELO, 1998), cacaueiro (ALMEIDA et al., 1993) sendo que as hifas do Verticillium entram nas raízes e depois se desenvolvem dentro dos tecidos vasculares, prejudicando a absorção de água, promovendo o declínio das plantas e consequentemente da produção (SOWIK et al., 2016).

\section{2) Sclerotium rolfsii (murcha de esclerócio)}

O fungo Sclerotium rolfsii é um fungo patogênico com forma de vida necrotrófica e presente em numerosas plantações em todo o mundo, ocorre comumente nos trópicos, regiões subtropicais e outras regiões temperadas quentes (PUNJA, 1985). Tem uma extensa gama de hospedeiros, apresenta pelo menos 500 espécies em 100 famílias suscetíveis, e seus hospedeiros mais comuns são leguminosas, crucíferas e cucurbitáceas (PUNJA, 1985). A podridão do caule é uma das graves doenças transmitidas pelo solo na cultura do amendoim causado por Sclerotium rolfsii contribuindo com 20 a 25\% das perdas de rendimento médio (ADIVER, 2003). Acomete também culturas de grande importância econômica como tomate (BARBOSA et al., 2010), soja (EMBRAPA, 2002), arroz, cana-de-açúcar e feijão (MICHEREFF et al., 2005), dentre outras, contribuindo significativamente para redução da produtividade.

Sclerotium rolfsii é capaz de produzir enorme quantidade estruturas de sobrevivência no solo, como escleródios, permanecendo viável durante vários anos

ENCICLOPÉDIA BIOSFERA, Centro Científico Conhecer - Goiânia, v.15 n.28; p.782 2018 
(SINGH et al., 2014). Sua disseminação se dá principalmente via sementes contaminadas (MARINO et al., 2008), material propagativo, restos culturais e solo contaminado (MICHEREFF et al., 2005). Dessa forma, o manejo desse patógeno através de fungicidas químicos é dificultado e muitas vezes não é eficaz, uma vez que exige grande quantidade de pesticidas para reduzir sua população, levando a contaminação do solo e poluição ambiental (SINGH et al., 2014).

\section{3) Macrophomina phaseolina (podridão da raiz)}

Macrophomina phaseolina é um fungo necrotrófico que apresenta uma ampla gama de hospedeiros, sendo responsável por causar perdas econômicas em mais de 500 espécies de plantas cultivadas pertencentes a 75 famílias botânicas (ISLAM et al., 2012). M. phaseolina é um patógeno que vive no solo, sendo capaz de infectar plantas de soja em diferentes estádios de desenvolvimento, e apresenta difícil controle por produzir microescleródios no solo (fonte primária de inóculo). Condições de temperatura alta do solo e baixo potencial hídrico são favoráveis para o desenvolvimento da doença, pois condicionam a germinação do microescleródio e produção de massa de hifas, sendo que estas crescem em direção as raízes dos hospedeiros, colonizando-as durante as primeiras semanas de desenvolvimento das plântulas (REYES-FRANCO et al., 2006).

A doença provoca redução no estande das plantas no campo, baixa qualidade de sementes, além de induzir a maturação precoce e morte das plantas. Em tecidos infectados, o fungo produz microescleródios em grande quantidade, os quais consistem na principal fonte de inóculo desse patógeno. Com a decomposição desses tecidos, os microescleródios são liberados no solo, onde sobrevivem por anos, sob condições adversas, principalmente em condições de temperaturas elevadas e estresse hídrico. A disseminação ocorre através de implementos agrícolas, águas de irrigação, vento, animais, além de sementes contaminadas (BIANCHINI et al., 1997). A fonte de inóculo primário é constituída pela semente infectada, pelo micélio do fungo colonizando restos de cultura e pelos escleródios que germinam após a quebra da dormência infectando a base do caule das plântulas (DHINGRA; SINCLAIR, 1978).

Durante os estádios iniciais de infecção do patógeno na cultura da soja, não são verificados sintomas visíveis nos órgãos aéreos das plantas, pois o patógeno permanece latente (PRATT, 2006). Quando as plantas se aproximam do final da estação de crescimento e o patógeno entra em sua fase necrotrófica e as plantas iniciam a sintomatologia com murchas e necrose devido ao bloqueio de feixes vasculares através de suas estruturas, secreção de enzimas e toxinas patogênicas (GUPTA et al., 2012). Nas plantas de soja, os sintomas baseiam-se na aparência preta e empoeirada do fungo no caule, vagens e sementes, bem como o escurecimento dos tecidos vasculares e radiculares (MENGISTU et al., 2011).

\section{4) Rhizoctonia (Rizoctoniose, mela ou requeima)}

Rhizoctonia solani é um fungo patogênico do solo, conhecido por apresentar uma ampla gama de hospedeiros, sendo grande ameaça em todo o mundo (AGRIOS, 2005). 
Temperaturas mais baixas $\left(15-18^{\circ} \mathrm{C}\right)$ associadas com alta umidade favorecem 0 tombamento de plântulas (NECHET; HALFELD-VIEIRA, 2006). Este fungo apresenta grande capacidade competitiva saprofítica e que sobrevive colonizando restos de cultura ou mediante estruturas de resistência chamadas de escleródios (CUBETA ; VILGALYS, 1997). Após a germinação dos escleródios e produção de micélio, o fungo penetra nas raízes e colo de plantas através da infecção direta, por ferimentos e aberturas naturais.

As plântulas apresentam na região do colo e raízes, pequenas manchas encharcadas, as quais vão aumentando, e resultam em podridão seca, de coloração castanha a castanho-avermelhada. É comum o estrangulamento nesta região da haste, resultando em murcha, tombamento ou sobrevivência temporária com emissão de raízes adventícias acima da região afetada. Entretanto, as plantas frequentemente tombam antes da floração. A morte em reboleira ocorre em plantas adultas, em anos chuvosos, com temperaturas amenas (ALMEIDA et al., 1997).

Particularmente para a soja, que é a principal cultura de grãos do Brasil, totalizando, na safra 1998/99, 12.900 .500 ha em área plantada, e uma produção de 31.241 .200 toneladas, várias doenças já foram associadas a $R$. solani, dentre estas tombamento, morte em reboleira, podridão de raiz e da base da haste e mela ou requeima da soja (EMBRAPA , 1999). Na cultura da batata é comum que ocorram sintomas como casca negra, apresentando grande importância nas áreas de cultivo, por afetar o desenvolvimento da batata desde a emergência até a colheita (BOKHARI et al., 2015). Já na cultura do feijão, a Rhizoctonia solani reduz o estande causando tombamento de plântulas, causa lesões necróticas nas folhas e pode levar a uma perda de rendimento de $100 \%$ (GHINI; ZARONI, 2001). O sintoma mais comum de $R$. solani no feijoeiro são lesões na interface raiz-parte aérea, resultando no tombamento.

5) Pythium sp. (tombamento de plântulas)

O tombamento de plântulas causado pelo fungo necrotrófico Pythium sp. é uma das mais importantes doenças em sistemas florestais e agrícolas, estando associados a lesões e podridões radiculares (WEILAND, 2011). Patógenos contaminantes do solo, como Pythium são difíceis de controlar, devido à sua longevidade no solo, capacidade de superar ou evitar as defesas das plantas e a logística, custo e eficácia das aplicações de fungicidas. Em muitos casos, os patógenos causam doenças em mais de uma espécie hospedeira, confundindo medidas de rotação (OKUBARA et al., 2014).

$\mathrm{Na}$ ausência de resíduos de hospedeiros, o fungo Pythium sp. apresenta capacidade de sobreviver no solo através de oósporos com paredes espessas, tornando-os particularmente duradouros no campo (ALMASIA et al., 2008). Muitas vezes, a infecção radicular e a ausência de lesões visíveis dificultam o diagnóstico da doença. No campo, as plantas apresentam baixa estatura, redução da emergência, redução do vigor das plântulas e tombamento (ALMASIA et al., 2008).

Os sintomas de tombamento e podridões radiculares ocasionadas pelo Phythium podem ser verificados em culturas como a do feijoeiro (Bianchini et al. 1997), a da soja (Henning et al. 1995) e a do tomateiro (Jones et al. 1993). Tubérculos de batata também podem sofrer danos pós-colheita por muitas espécies de Pythium, agentes

ENCICLOPÉDIA BIOSFERA, Centro Científico Conhecer - Goiânia, v.15 n.28; p.784 2018 
causadores do apodrecimento. O fungo entra através de feridas e induzem zonas necróticas aquosas e enegrecidas dentro do tubérculo (PETERS et al., 2005).

\section{6) Phytophthora infestans (requeima)}

Phytophthora infestans é um fungo bastante conhecido, associado a doença requeima da batata, infectando não apenas as folhagens, mas também os tubérculos (WHISSON et al., 2016). Uma vez infectados pelo patógeno, as plantas declinam rapidamente e podem ser mortas em questão de horas (FRY et al., 2015), causando perdas devastadoras aos produtores de batata. É considerado uma ameaça à segurança alimentar por causar perdas econômicas de 6 bilhões de dólares anualmente (DEREVNINA et al., 2016). Acomete também culturas como o Citrus, reduzindo em torno de $30 \%$ da produção (PANABIERES et al., 2016), atacam desde o viveiro, causando tombamento e podridão radicular, e em campos causando podridão do caule (gomose), podridão radicular e até mesmo podridão dos frutos, interferindo na póscolheita (BOWMAN et al., 2007).

Phytophthora é também comum em lavouras de soja causando podridão de sementes, tombamento pré e pós-emergente, podridão de caules e raízes (CHANG et al., 2017). O sintoma mais característico é a descoloração marrom do caule logo acima do solo, podendo se espalhar para ramos laterais inferiores. Mudas infectadas tornamse marrons, murcham e acabam morrendo (WRATHER et al., 2001). O patógeno se reproduz rapidamente, sendo favorecido pela umidade alta e temperatura amena, além de sua disseminação ser facilitada na presença de precipitação em estações chuvosas (HUBERLI et al., 2011).

\section{7) Fusarium sp. (murcha de Fusarium)}

Fusarium oxysporum é um dos fungos fitopatogênicos mais conhecidos devido à sua importância econômica (GEISER et al., 2013). Além disso, apresenta ampla distribuição por acometer inúmeros hospedeiros. O fungo patogênico Fusarium oxysporum é conhecido por causar podridão radicular e murcha em mais de 100 espécies de plantas (AGRIOS, 2005). Este é o agente causal da murcha de Fusarium em culturas como o tomate (MCGOVERN, 2015), banana (GHAG et al., 2015), pimentão (JABER et al., 2018), dentre outras, resultando em perdas severas na produção.

O fungo persiste no solo por meio de clamidósporos (estruturas de resistência) e permanece viável por várias estações, o que dificulta seu manejo (SINGH et al., 2010). O desenvolvimento da doença é favorecido por temperaturas do solo e do ar em torno de $28^{\circ} \mathrm{C}$. Dessa forma, com condições ambientais favoráveis o fungo germina e ocorre sua penetração nas raízes do hospedeiro, entrando no sistema vascular e utilizando dos vasos do xilema para colonizar o hospedeiro e promover o entupimento dos vasos com micélio ou esporos. Este entupimento causa descoloração vascular e foliar, baixa estatura das plantas, amarelecimento das folhas mais velhas, murcha e frequentemente levando a morte das plantas (MCGOVERN, 2015).

8) Scleriotinia sclerotiorum (mofo branco) 
O fungo Sclerotinia sclerotiorum é um patógeno cosmopolita que provoca podridão de raiz (mofo branco) em cerca de 400 espécies de plantas pertencentes a 75 famílias se as condições ambientais forem adequadas (ALKOORANEE et al., 2015). Dentre as culturas mais infectadas pode ser citadas: a colza, o tomate, a batata, a soja e o girassol (LYU et al., 2016). Esse fungo infecta principalmente caules, folhas e flores na forma de escleródios (estrutura de sobrevivência) que residem no solo por muitos anos e depois germinam formando micélios na superfície das plantas (CLARKSON et al., 2013). Sua disseminação se dá principalmente por sementes infectadas. A germinação carpogênica de escleródios pode liberar muitos ascósporos transportados pelo ar, que são de difícil controle, fazendo que o mofo branco seja uma das doenças mais prejudiciais economicamente (SUN et al., 2017).

Os primeiros sintomas são manchas aquosas que evoluem para coloração castanho-clara e logo desenvolvem abundante formação de micélio branco e denso. $O$ fungo é capaz de infectar qualquer parte da planta, porém, as infecções iniciam-se com frequência a partir das inflorescências e das axilas das folhas e dos ramos laterais. Ocasionalmente, nas folhas, podem ser observados sintomas de murcha e seca. Em poucos dias, o micélio transforma-se em massa negra e rígida, o esclerócio, que é a forma de resistência do fungo. Este micélio evolui seu crescimento no interior do caule, impedindo transporte de água e minerais, ocasionando a morte da planta (HENNING et al., 2005).

\section{9) Meloidogyne (Nematoide das galhas)}

O nematoide das galhas (Meloidogyne) apresenta estilo de vida como endoparasita sedentário, ou seja, interagem com seus hospedeiros de uma maneira mais complexa. Eles infectam o hospedeiro através de suas raízes e induzem a rediferenciação das células da raiz no local de alimentação do nematoide, chamadas de células gigantes. Uma vez dentro das raízes, os nematoides extraem importantes nutrientes (água, íons e lipídios) necessários para sua vida a partir das plantas, causando graves danos a cultura hospedeira, pois bloqueia ou dificulta o fluxo de água e nutrientes (ABAD; WILLIAMSON, 2010).

A presença de nematoides Meloidogyne no solo é um fator limitante para a produção de hortaliças (VERDEJO-LUCAS; CASTILLO, 2011). Perdas de colheitas devido a presença de nematoides do gênero Meloidogyne são difíceis de calcular, porque dependem de diversos fatores, como tamanho e adequação das populações de nematoides no início da safra, condições ambientais, genótipo da cultura (genes de resistência) e enxertia em porta-enxertos tolerantes/resistentes. Alguns autores estimam a incidência de Meloidogyne entre 20 e $40 \%$ da superfície total cultivada, e a perda média de produtividade é de 30,8\% (TALAVERA et al., 2012).

A sobrevivência dos nematoides pode ser favorecida pela presença de plantas hospedeiras na área, restos culturais, temperaturas amenas e umidade no solo (CAMPOS et al., 2006). Assim, a desinfestação do solo é necessária para reduzir as populações de nematoides no solo, a fim de obter colheitas de sucesso e produções lucrativas. 


\section{0) Pratylenchus (Nematoide das lesões radiculares)}

Os nematoides das lesões radiculares do gênero Pratylenchus são endoparasitos migratórios, pertencentes à família Pratylenchidae. Os nematoides das lesões são classificados como o terceiro grupo mais importante de nematoides parasitas de plantas em termos de perda econômica na agricultura e horticultura (CASTILLO; VOVLAS, 2007). Em alguns casos, a perda de rendimento pode se estender até $85 \%$ da produção esperada (NICOL et al., 2011). Várias espécies de Pratylenchus, como $P$. penetrans, $P$. brachyurus, $P$. coffeae e $P$. vulnustem apresentam ampla distribuição geográfica e pode parasitar uma ampla gama de plantas hospedeiras (CASTILLO; VOVLAS, 2007). No entanto, o diagnóstico morfológico de nematoides das lesões radiculares é problemático devido ao baixo número de características diagnósticas e alta variabilidade intraespecífica (CASTILLO; VOVLAS, 2007).

$\mathrm{Na}$ parte aérea das plantas de citrus, os sintomas da doença são expressos na forma de folhas e frutos menores do que nas plantas sadias, seguidos de depauperamento gradual da planta. A clorose e o enrolamento de folhas, e a morte descendente das plantas são sintomas adicionais que refletem pobre desenvolvimento de raízes e apodrecimento de radicelas, resultantes da interação dos nematóides com fungos, bactérias e outros microrganismos da rizosfera, concorrendo para a deterioração do sistema radicular (NYCZEPIR; BECKER, 1998). Segundo Campos (2007), as condições de temperatura e precipitação pluviométricas são fatores ambientais que regulam a população de $T$. semipenetrans e $P$. jaehni no Estado de São Paulo, sendo que os níveis populacionais mais baixos foram detectados no verão (dezembro - março), correspondendo aos meses mais quentes e chuvosos, enquanto os picos de população dos nematóides ocorreram nos meses mais frios e secos.

\section{1) Heterodera glycines (Nematoide do cisto da soja)}

O nematoide do cisto da soja (Heterodera glycines) (NCS), juntamente com a podridão radicular e doenças de plântulas, são citados como principais causas de perda de rendimento nas regiões produtoras de soja em todo o mundo (MUELLER et al., 2016). O NCS é uma praga destrutiva em muitas regiões, e está associado a redução da produtividade em muitas lavouras.

O nematoide Heterodera glycines é um parasita obrigatório em plantas de soja e é conhecido por formar cistos nas raízes de seus hospedeiros. Quando o nematoide na sua fase juvenil infecta a raiz com seu estilete, rapidamente induz a formação de uma célula nutridora, chamada de "sincício". O nematoide utiliza desta célula para alimentação e fornecimento de nutrientes necessários para seu desenvolvimento até a fase adulta, ficando preso na raiz. $\mathrm{Na}$ fase reprodutiva ele fica preso na raiz e encista para o lado de fora, por isso é conhecido como o nematoide do cisto da soja. Se ocorrer morte da célula nutridora, consequentemente ocorre morte do nematoide (MICTHUM, 2016).

12) Dytilenchus dipsaci (nematoide do alho)

O nematoide Ditylenchus dipsaci é o principal parasita da cultura do alho e da ENCICLOPÉDIA BIOSFERA, Centro Científico Conhecer - Goiânia, v.15 n.28; p.787 2018 
cebola, e apresenta distribuição em todas as regiões produtoras do Brasil (CHARCHAR et al., 2003). Sua importância econômica deve se a são grande distribuição e as mais de 500 espécies de plantas de 40 famílias que são consideradas hospedeiras. $D$. dipsaci vive principalmente como endoparasita em partes aéreas de plantas (caules, folhas e flores), mas também ataca bulbos, tubérculos e rizomas. Os sintomas comuns de infestação são inchaço, que consiste no entumescimento das células vegetais atacadas, promovendo distorção, descoloração e nanismo de partes de plantas acima do solo, e necrose de bulbos e tubérculos. Os limiares econômicos deste nematoide são na sua maioria muito baixas e mesmo densidades populacionais de apenas 10 nematoides por $0,5 \mathrm{~kg}$ de solo podem ocasionar grandes perdas (SEINHORST, 1956).

Um dos fatores que dificultam seu controle é a capacidade de anibrobiose no quarto instar juvenil que o torna despercebido a olho nu e promove ampla disseminação (PINHEIRO et al., 2014). Além disso, poucos produtos químicos são liberados pelo Ministério da Agricultura Pecuária e Abastecimento para controlar essa praga agrícola (MAPA, 2018).

\section{FORMAS GERAIS DE CONTROLE}

A supressividade do solo no mesmo local varia de acordo com as práticas de manejo a longo prazo empregadas (TAMM et al., 2010). Assim, a manipulação do manejo do solo tem um enorme potencial para aumentar a capacidade dos solos agrícolas em suprimir doenças de plantas. As atuais recomendações de manejo do solo para aumentar a supressividade dos agentes patogênicos baseiam-se no aumento de insumos orgânicos para o solo, reduzindo os distúrbios como a movimentação dos solos e diversificando a rotação de culturas.

Stirling (2013) salienta que o manejo adequado do solo seja realizado incluindo o cultivo mínimo, rotação de culturas, adubação verde e cobertura morta com resíduos de culturas, sendo dessa forma eficientes para redução da densidade de microrganismos (fungos, bactérias e nematoides) patogênicos às plantas. Quando todas as medidas de manejo são utilizadas adequadamente, as lavouras tendem a contribuir para maior sustentabilidade ambiental e menor número de infestações, apresentando maior lucratividade final.

\section{1) Rotação de culturas}

O principal objetivo de realizar a rotação de culturas é reduzir o contato entre o agente patogênico e o hospedeiro suscetível, para diminuir a taxa de infecção e o consequentemente avanço da doença. Trata-se de uma ferramenta antiga, eficiente e menos agressiva ao ambiente. Assim contribui para a sustentabilidade ecológica da agricultura. Na rotação, os restos são mineralizados pela ação de decomposição dos microrganismos do solo de maneira que o inóculo é eliminado ou mantido abaixo do valor numérico de infecção. Através da rotação se pode controlar os patógenos que sobrevivem nos restos culturais e que não possuem estruturas de resistência como esclerócios, clamidosporas como ocorre na maioria das culturas (CARMONA, 2006).

A rotação de culturas contribui para o controle de doenças, eliminando hospedeiros alternativos e potencial de inóculo para a cultura subsequente, porém, devido a versatilidade dos fitopatógenos, isso pode não ocorrer em todas as rotações

ENCICLOPÉDIA BIOSFERA, Centro Científico Conhecer - Goiânia, v.15 n.28; p.788 2018 
(BERNI et al., 2002). Desta forma, rotação de culturas pode ser mais eficiente na promoção da alteração qualitativa na microflora do solo, favorecendo o estabelecimento e crescimento de microrganismos antagônicos aos patógenos (BERNI et al., 2002).

As diferentes espécies vegetais exploram um conjunto específico nutricional e deixam de utilizar outros nutrientes, esse é o processo natural do crescimento da planta, porém, a exploração nutricional pelas plantas pode ser revertido para manter a produtividade ou melhorá-la. Existem várias maneiras de devolver a vitalidade e os nutrientes do solo, dentre estas estão a rotação de culturas e o pousio. A rotação de culturas ainda permite a diversificação da exploração dos nutrientes fornecidos e a possível restauração daqueles minorados na cultura anterior (CIRNE; SOUZA, 2014). Já, o pousio mantém certo período sem cultivo para restabelecer os nutrientes perdidos e a atividade microbiológica.

A rotação de culturas milho-feijão combinado com o preparo do solo com grade reduziu a incidência de Fusarium solani f. sp. phaseoli, que causa podridões radiculares em feijoeiro (BERNI et al., 2002). Diversos fungos podem ser controlados pela rotação de culturas, tais como, Ascochyta, Phoma, Phomopsis, Phylosticta, Stagonospora, Septoria, Fusarium, Microdochium, Colletotrichum, Cylindrosporium, Marssonnina, Sphaceloma, Drechslera, Diplodia, Cercospora e Colletotrichum (REIS et al., 2011). Gramíneas de inverno como trigo, cevada, aveia e azevém e seus restos culturais são fonte de inoculo para muitos fungos, sendo assim, a cultura do milho cultivada posterior a estas culturas não seria um bom manejo, devido ao inoculo estar presente na área (REIS et al., 2011).

A rotação de culturas com soja no verão anterior e azevém no inverno, reduz a incidência de podridões do colmo em milho no verão (DENTI; REIS, 2001). A estratégia de modificação das culturas presentes na área, a partir da rotação e não da sucessão de culturas, auxilia na modificação dos organismos predadores e da microflora do solo, modificação do tamanho das raízes no solo, na liberação de exsudatos radiculares, além de cortar o ciclo de muitas doenças pela inanição de alimento, promovendo a supressividade.

\section{2) Cultivares resistentes}

A utilização de cultivares resistentes é a primeira estratégia de manejo durante o planejamento de uma lavoura por ser relativamente barata. Dessa forma, no planejamento é recomendável optar-se por sementes que contenham grande espectro de resistência. A resistência é uma ferramenta que deve ser utilizada com cautela, pois se o cultivo de plantas resistentes não for composto também por plantas suscetíveis, corre risco dos microrganismos superarem essa resistência, tornando-se também resistentes e causando doença para o cultivo em questão. Dessa forma, a durabilidade da resistência de uma planta pode ser caracterizada pelo tempo de aparecimento de isolados virulentos ou pelo momento de invasão de isolados virulentos, levando a perda de rendimento (VAN DEN BOSH; GILLIGAN, 2003).

Dois tipos de resistência de plantas são geralmente reconhecidos: resistência qualitativa condicionada por um único gene e resistência quantitativa condicionada por múltiplos genes de efeito parcial, com tipos intermediários entre esses extremos (POLAND et al., 2009). Dessa forma, desenvolver estratégias apropriadas que integrem 
cultivares resistentes em sistemas de cultivo são, portanto, necessárias para reduzir a quantidade de inóculo das populações de patógenos, a fim de aumentar a eficiência do controle da doença e reduzir a capacidade de adaptação de patógenos para superar a resistência da planta.

Estratégias integrando cultivares resistentes com saneamento e tratamentos fungicidas reduzidos têm sido propostas para redução de epidemias (JOHNSON, 2012). Para patógenos de solo, a utilização de plantas resistentes é uma estratégia bastante difundida e utilizada, contudo, não existem cultivares resistentes para a maioria dos patógenos de solo, e quando existem a resistência é moderada, ou de fácil adaptação pelos patógenos.

\section{3) Controle físico}

A desinfestação do solo é uma das abordagens para o controle de doenças radiculares e vasculares que são especialmente comuns em lavouras intensivas e de alto valor, por exemplo, em plantações de hortaliças e em estufa. É uma abordagem sofisticada, cara e eficaz de controle que traz grandes vantagens. O princípio básico é eliminar um amplo espectro de organismos nocivos no solo antes do plantio, geralmente usando meios químicos ou físicos drásticos. Embora o objetivo principal da desinfestação do solo seja eliminar as principais pragas quando suas populações atingem níveis economicamente intoleráveis, benefícios adicionais (embora inicialmente não intencionais) também podem ser obtidos. A eliminação de agentes bióticos e abióticos prejudiciais que se acumulam no solo ao longo de sua longa história de cultivo é um exemplo de tal benefício. No entanto, devido à natureza drástica da desinfestação do solo, ela também pode ter um efeito prejudicial em componentes bióticos e abióticos não-alvo do solo (KATAN; GAMLIEL, 2014).

A desinfestação do solo consiste em quatro abordagens. Os dois primeiros - vapor e fumigação - foram desenvolvidos no final do século XIX, e nos dias de hoje a fumigação com produtos químicos está banida devida a sua agressividade. Uma terceira abordagem é a solarização do solo (também chamada de aquecimento solar). A biofumigação ou biodesinfestação baseada na incorporação de resíduos orgânicos sob cobertura de plástico é uma quarta abordagem que ganhou interesse nos últimos anos (KATAN; GAMLIEL, 2014).

Dentre os métodos físicos, a solarização é um dos métodos mais utilizados, contudo apresenta especificidade para pequenas áreas devido a sua eficiência econômica ser restrita para grandes áreas. A solarização depende das condições meteorológicas, principalmente do sol e sua temperatura de aquecimento, o que deve ser analisado antes de iniciar o processo de solarização, pois em determinados locais e estações não há temperaturas suficientes para aquecimento durante o dia. Princípios básicos da solarização: solo úmido coberto com plástico transparente, em período com alta irradiação, dia longos e temperatura elevada (GAMLIEL; KATAN, 2012).

O número de pragas do solo controladas efetivamente pela solarização é muito grande. Alguns patógenos que são altamente sensíveis à solarização, por exemplo, $V$. dahliae e espécies de Phytophthora, foram efetivamente controlados na maioria dos estudos, enquanto o nível de controle de patógenos moderadamente tolerantes ao calor, como o Sclerotium rolfsii, varia de local para local. Certos patógenos e ervas

ENCICLOPÉDIA BIOSFERA, Centro Científico Conhecer - Goiânia, v.15 n.28; p.790 2018 
daninhas, no entanto, não são efetivamente controlados pela solarização, como os fungos tolerantes ao calor dos gêneros Macrophomina e Monosporascus. Isto não é surpreendente, uma vez que não se pode esperar que nenhum método de controle único seja eficaz contra todas as pragas (KATAN; GAMLIEL, 2014).

Silva et al., (2006) avaliando a interação entre o método físico da solarização associada a adubação com amônio, verificaram redução da diversidade de nematoides na camada de $10-20 \mathrm{~cm}$ do solo, além da redução do número de galhas, número, massa de ovos e a população de nematoides fitoparasitas, em especial de Meloidogyne spp. O método de solarização, dessa forma, sozinha ou incrementada com outra técnica apresenta potencial para controle de nematoides e redução do uso de agrotóxicos.

\section{4) Controle biológico}

O controle biológico consiste na aplicação de interações naturais que levam a relações entre as espécies, buscando o controle do equilíbrio entre as populações, oferecendo uma série de benefícios, como maior especificidade de alvos e rápida degradação. Além disso, os produtos desenvolvidos para o controle biológico possuem uma variedade de ferramentas a serem utilizadas isoladamente ou em associação com outros métodos de controle (CORDEAU et al., 2016; SUTTON et al., 2016). Os fungos fitopatogênicos atuam nas plantas através da produção de toxinas que podem causar lesões e déficits no desenvolvimento das plantas (DE SOUZA et al., 2015).

As rizobactérias antagonistas foram consideradas a melhor escolha de agentes de biocontrole (BCAs) para o controle da murcha bacteriana do tomateiro. De fato, vários estudos no passado obtiveram com sucesso rizobactérias como Pseudomonas spp. (LEMESSA; ZELLER, 2007), Bacillus spp., Flavobacterium johnsoniae e Chryseobacterium daecheongense (HUANG et al., 2013) que têm forte capacidade de biocontrole contra murcha bacteriana sob condições de laboratório e/ou estufa.

A qualidade dos produtos disponíveis para biocontrole nem sempre é adequada, o que colabora com as dificuldades em sua adoção em maior escala. A produção em larga escala dos agentes de biocontrole desenvolvidos no Brasil é realizada, em geral, com baixo nível tecnológico, pois a infra-estrutura para o desenvolvimento dos agentes de biocontrole é deficitária. A maioria dos produtos não é submetida a estudos rigorosos de pré-formulação, formulação e controle de qualidade, os agentes de biocontrole apresentam dificuldade de registro, pois a legislação para registro é a mesma utilizada para os agrotóxicos (MORANDI; BETTIOL, 2009).

\section{5) Controle químico}

O manejo de patógenos de solo se destaca entre os grandes desafios enfrentados pela agricultura atual. A possibilidade de sobrevivência destes microorganismos como saprófitas no solo a dificuldade de se atingir o alvo com a maioria dos métodos padrão de aplicação de produtos fitossanitários, somados à ausência de sistemicidade basipetal (de cima para baixo) dos fitossanitários registrados, tornam o controle químico dessas doenças uma prática de baixa eficiência. Em alguns casos esses compostos químicos não matam os fungos, apenas inibem, temporariamente, a germinação dos

ENCICLOPÉDIA BIOSFERA, Centro Científico Conhecer - Goiânia, v.15 n.28; p. 791 2018 
esporos. O fenômeno de inibição temporária da germinação ou de crescimento fúngico é denominado "Fungistase" e os produtos com essas propriedades são "Fungistáticos" (DALIO, 2013).

Para as práticas de controle recomendadas para o tombamento de plântulas, o tratamento das sementes com fungicidas eficientes assume um importante papel, sendo considerado, até o momento, a principal medida a ser adotada e a opção mais segura e econômica para minimizar os efeitos negativos destas doenças. Tratamentos de sementes com fungicidas protegem as plântulas do ataque de patógenos no inicio do seu desenvolvimento, contudo, se a área estiver com alta infestação, a proteção do inicio do cultivo não será suficiente para proteger o cultivo até o período de colheita (GASPAR et al., 2015).

Estudos recentes propuseram que tratamento de sementes com fungicidas e inseticidas podem ser profilaticamente usados para aumentar o rendimento em diversos ambientes, aumentando assim a lucratividade (GASPAR et al., 2015). De 1996 a 2013, o uso do tratamento de sementes aumentou de $8 \%$ para mais de $75 \%$ em cultivos de soja plantada nos Estados Unidos (MUNKVOLD et al., 2014).

As opções comerciais de tratamento de sementes geralmente incluem vários fungicidas que visam diferentes organismos gerados pelo solo. Os fungicidas metalaxil e outros fungicidas de fenilamida são usados para controlar doenças de oomicetos causados por Phytophthora e Pythium spp. (DORRANCE et al., 2009). Outros fungicidas, incluindo fludioxonil e estrobilurinas, são usados para controlar fungos como o Fusarium spp. e Rhizoctonia solani (ELLIS et al., 2011). Os tratamentos de sementes também podem incluir um nematicida ou protetor biológico para mitigar os danos do nematoide do cisto da soja (GASPAR et al., 2014). Para a cultura do feijão, o tratamento de sementes com fungicidas correspondeu a notáveis melhoras na produtividade além da redução da epidemia de doenças radiculares em lavouras de feijão (NASERI et al., 2016; NASERI; MORADI, 2015).

Para o controle de nematoides na cultura da soja, a utilização de nematicidas como o carbofurano apresenta resultados positivos (ARAUJO et al., 2012). Para a cultura do tomate são recomendados nematicidas como abamectina, fenamifós, metam-sódico e fluensulfona (MAPA, 2018). O nematicida sistêmico do grupo organofosforado, fenamifós, por ser granulado, deve ser aplicado nas covas de plantio do tomate, antes ou durante o transplante das mudas (MAPA, 2018). Contudo, os nematicidas químicos tem seu uso cada vez mais restrito, por sua alta toxicidade e baixa eficiência de controle, após repetidas aplicações (DONG; ZHANG, 2006).

\section{6) Controle cultural}

O controle cultural das doenças consiste basicamente na manipulação das condições de pré-plantio e durante o desenvolvimento do hospedeiro em detrimento ao patógeno, objetivando a prevenção ou a intercepção da epidemia por outros meios que não sejam a resistência genética e o uso de pesticidas. O objetivo primário do controle cultural é reduzir o contato entre o hospedeiro suscetível e o inóculo viável, de maneira a reduzir a taxa de infecção e o subsequente progresso da doença (Rotem \& Palti, 1980). De um modo geral, pode considerar-se que as medidas de controle cultural

ENCICLOPÉDIA BIOSFERA, Centro Científico Conhecer - Goiânia, v.15 n.28; p.792 2018 
visam evitar a doença ou suprimir o agente causal, objetivando, portanto, a obtenção de plantas sadias mais do que controlar o agente causal.

Segundo Rotem e Palti (1980), são três os princípios que fundamentam o controle cultural: a) supressão do aumento e/ou a destruição do inóculo existente; b) escape das culturas ao ataque potencial do patógeno e c) regulação do crescimento da planta direcionado à menor suscetibilidade. O potencial de controle cultural, ou por práticas culturais, está diretamente relacionado com a oportunidade de manipulação das condições de crescimento das plantas. As principais práticas culturais envolvidas no controle cultural são: rotação de culturas, manejo do solo e dos restos culturais, população adequada de plantas, irrigação, adubação verde, compostagem, fertilização do solo, época de plantio e profundidade de semeadura (ROTEM; PALTI 1980), sendo que todas estas técnicas influenciam no nível de inóculo do solo.

As técnicas utilizadas isoladamente nem sempre são suficientes para a obtenção de um controle adequado dos patógenos de solo principalmente, mas são fundamentais para o manejo integrado de pragas e doenças. A escolha da época adequada de semeadura é uma medida de controle eficiente uma vez que as baixas temperaturas favorecem a incidência e severidade do tombamento de plântulas (principalmente aquele causado por $R$. solani), recomenda-se evitar semeaduras anteriores meados de outubro (ENGELHARD, 1989).

Outro aspecto importante é o equilíbrio nutricional das plantas. Normalmente, a adubação é baseada nas necessidades de macronutrientes (NPK), não considerando os micronutrientes e outros elementos que podem ser benéficos para as plantas (ENGELHARD, 1989).

\section{7) Manejo integrado de doenças}

O manejo integrado consiste na integração de práticas de cultivo, que juntas apresentam melhor eficiência de controle. Dentre as técnicas inclusas no manejo integrado cita-se a rotação de culturas, escolha de época de plantio, uso de variedades resistentes, controle químico, físico e biológico dos microrganismos, uso de porta enxertos resistentes, dentre outros (BETTIO et al., 2006). A utilização de várias táticas auxilia na mortalidade dos microrganismos patogênicos, interferindo minimamente no ecossistema natural, reduzindo as chances dos insetos ou doenças se adaptarem a alguma prática defensiva em especial.

No agrossistema cultivo protegido, o manejo integrado de doenças significa que, além do uso racional e múltiplo das clássicas técnicas de controle, também deve se atuar sobre todos os componentes da cadeia produtiva (preparo do solo, seleção de cultivares e híbridos, fertilizações, irrigações, tratos culturais, manejo de pragas, etc). Estes componentes podem também ser relacionados à forma de controle de doença, pois otimizam a expressão do máximo potencial produtivo da cultura e consequentemente a redução da intensidade das doenças (ZAMBOLIM et al., 1999). Assim, o manejo integrado de doenças em hortaliças tem sido tratado como a utilização de métodos de controle de forma organizada, com efeito somatório e com viabilidade econômica, objetivando reduzir ao máximo o uso de produtos fitossanitários, mas garantindo a produção, onde os aspectos ecológicos e residuais desses produtos estão em primeiro lugar (ZAMBOLIM et al., 1997)

ENCICLOPÉDIA BIOSFERA, Centro Científico Conhecer - Goiânia, v.15 n.28; p.793 2018 
Além disso, o desenvolvimento do manejo integrado de doenças oferece uma possibilidade interessante de reduzir o uso de pesticidas, mas precisa ser sustentável para neutralizar a rápida evolução das populações de patógenos. De fato, as populações de patógenos são capazes de se adaptar; isso resulta na ineficiência de controle (BECKERMAN et al., 2015) ou na resistência dos mesmos. Dentro de um programa de manejo integrado de doenças, o controle químico deveria ser um dos últimos métodos a ser utilizado após esgotadas todas as medidas alternativas, ou deveria fazer parte de um conjunto de medidas para o controle de doenças na cultura instalada (ZAMBOLIM et al., 1997).

Para fungos como Fusarium solani, Rhizoctonia solani, Macrophomina phaseolina e Fusarium oxysporum que causam doenças radiculares em plantas de feijão, promovendo redução de até $65 \%$ do rendimento. Estes patógenos apresentam dificuldades de controle, sendo amplamente recomendadas técnicas integradas de manejo para controlar eficientemente as doenças (NASERI; HEMMATI, 2017).

O manejo de doenças de plantas enfrenta desafios cada vez maiores devido a: (i) aumento da demanda por alimentos totais, seguros e diversificados para apoiar a crescente população global e sua melhoria nos padrões de vida; (ii) reduzir o potencial de produção na agricultura devido à competição por terras em áreas férteis e esgotamento de terras aráveis marginais; (iii) deterioração da ecologia dos agroecossistemas e esgotamento dos recursos naturais; e (iv) aumento do risco de epidemias de doenças resultantes de intensificação agrícola e monoculturas. O futuro manejo de doenças de plantas deve ter como objetivo fortalecer a segurança alimentar para uma sociedade estável, ao mesmo tempo em que protege a saúde dos ecossistemas associados e reduz a dependência de recursos naturais (DUN CHUN et al., 2016). Dessa forma, a utilização do manejo integrado é uma forma eficaz de mitigar os problemas enfrentados no controle de doenças radiculares e vasculares.

\section{CONSIDERAÇÕES FINAIS}

Os patógenos de solo causadores de doenças de raízes e do sistema vascular são um grande problema nas áreas produtoras de alimentos em todo o mundo. A investigação dos principais patógenos causadores de doenças de solo levam em consideração os microrganismos: Verticillium, Sclerotium rolfsii, Macrophomina phaseolina, Rhizoctonia, Pythium sp., Phytophthora, Fusarium sp., Scleriotinia sclerotiorum, Ralstonia, Meloidogyne, Pratylenchus, Heterodera glycines e Dytilenchus dipsaci. Cada patossistema apresenta características intrínsecas e que modificam o manejo de controle da doença. Contudo, de modo geral, para a eficiência de controle é recomendável que sejam realizadas todas as medidas indicadas, priorizando o manejo integrado de doenças, a manutenção do equilíbrio ecológico e a redução da contaminação ambiental.

\section{REFERÊNCIAS}


ABAD, P.; WILLIAMSON, V. M. Plant nematode interaction: a sophisticated dialogue. In: Advances in botanical research. Academic Press, 2010. p. 147192. https://doi.org/10.1016/s0065-2296(10)53005-2

ADIVER, S. S. Influência de alterações orgânicas e componentes biológicos na podridão do caule do amendoim. Seminário Nacional de Manejo do Estresse em Sementes Oleaginosas para a Autossuficiência em Óleo Vegetal, Sociedade Indiana de Pesquisa de Sementes de Oleaginosas, Diretoria de Pesquisa de Sementes de Óleo, Formulário de Hyderabad (2003), p. 15-17, 28 a 30 de janeiro.

AGRIOS, 2005. Patologia Vegetal da GN Agrios, Academic Press, New York, 2005.

ALKOORANEE, J. T.; ALEDAN, T. R.; ALI, A. K.; XIANG J.; LU G. Y. et al. Systemic resistance induced in two genotypes of Brassica napus (AACC) and Raphanus oleracea $(\mathrm{RRCC})$ by Trichoderma isolates against Sclerotinia sclerotiorum. American Journal of Plant Sciences v. 6, n. 10, p. 1662-1674, 2015. https://doi.org/10.4236/ajps.2015.610166

ALMASIA, N. I.; BAZZINI, A. A.; HOPP, H. E.; VAZQUEZ-ROVERE, C. A superexpressão do gene snakin-1 aumenta a resistência a Rhizoctonia solani e Erwinia carotovora em plantas de batata transgênicas. Molecular Plant Pathology, v. 9, n. 9, p. 329-338, 2008. https://doi.org/10.1111/j.1364-3703.2008.00469.x

ALMEIDA, H. A.; ALMEIDA, L. C. C.; LIMA, A. A. Efeito da deficiência hídrica sobre o surgimento da murcha de Verticillium no cacaueiro. Anais, 8ํㅡㄹ Congresso Brasileiro de Agrometeorologia, Santa Maria, RS. 1993. p. 187.

ALMEIDA, A. M. R.; FERREIRA, L. P.; YORINORI, J. T.; SILVA, J. F. V.; HENNING, A. A. Doenças da soja. In: KIMATI, H., AMORIM, L., BERGAMIN FILHO, A., CAMARGO, L.E.A., REZENDE, J.A.M. (Ed.) Manual de fitopatologia: doenças das plantas cultivadas. São Paulo: Agronômica Ceres, 1997. v. 2, cap.61, p. 642-64.

ANDERSON, J. A.; ARSYAD, T. R.; TAN, D. M.; PLOPER, Y.; PORTA-PUGLIA, L. D.; YORINORI, J. T. Estimativas de perda de doenças da soja para os dez principais países produtores de soja em 1998. Canadian Journal of Plant Pathology, v. 23, n. 2, p. 115-121, 2001. https://doi.org/10.1080/07060660109506918

ATALLAH, Z. K.; HAYES, R. J.; SUBBARAO, K. V. Fifteen years of Verticillium willow lettuce in the American salad bowl: a tale of immigration, subjugation and reduction. Plant Disease, v. 95, p. 784-792, 2011.

BACCHI, L. M. A.; GOULART, A. C. P.; DEGRANDE, P. D. Revista Cultivar: Doenças no solo. v. 32, 2001. Disponível em: <https://www.grupocultivar.com.br/artigos/doencas-no-solo>. Acesso em: 05 nov. 2018.

BECKERMAN, J. L.; SUNDIN. G. W.; ROSENBERGER, D. A. Do some concepts of IPM contribute to the development of resistance to fungicides? Lessons Learned from the Apple Scabies Scabsystem in the United States. Pest Management Science, v. 71, p. 331-342, 2015. 
EMBRAPA SOJA. (Brasil). Tecnologias de produção de soja região central do Brasil 2003. Londrina: EMBRAPA Soja, 2002. 199p.

EMBRAPA. Recomendações técnicas para a cultura da soja na região central do Brasil 1999/2000. Londrina: Embrapa Soja, 1999. 226p. (Documentos, 132).

ENGELHARD, A. W. Soilborne plant pathogens: management of diseases with macroand microelements. The American Phytopathological Society, p. 217, 1989.

ELLIS, M. L., BRODERS, K. D., PAUL, P. A., \& DORRANCE, A. E. Infection of soybean seed by Fusarium graminearum and effect of seed treatments on disease under controlled conditions. Plant disease, v. 95, n. 4, p. 401-407, 2011. https://doi.org/10.1094/PDIS-05-10-0317

FREDDO, Á. R.; MAZARO, S. M.; BORIN, M. D. S. R.; BUSSO, C.; CECHIN, F. E. et al. Redução no tombamento de Fusarium sp. em plântulas de beterraba, pelo tratamento das sementes com óleo essencial de Aloysia citriodora Palau. Scientia Agraria Paranaensis, v. 15, n. 4, p. 453-459, 2016. http://dx.doi.org/10.1818/sap.v15i4.13451

FRY, W. E.; BIRCH, P. R. J.; JUDELSON, H. S.; GRÜNWALD, N. J. et al. Five reasons to consider Phytophthora infestans a reemerging pathogen. Phytopathology, v. 105, n. 7, p. 966-981, 2015. https://doi.org/10.1094/PHYTO-01-15-0005-FI

FURLAN, S. H. Mofo branco. Doenças da Soja: Melhoramento genético e técnicas de manejo, p. 53-72, 2015.

GAMLIEL, A.; KATAN, J. (Ed.). Soil solarization: Theory and practice. St. Paul, MN: American Phytopathological Society, 2012.

GASPAR, A. P.; MARBURGER, D. A.; MOURTZINIS, S.; CONLEY, S. P. Soybean seed yield response to multiple seed treatment components across diverse environments. Agronomy Journal, v. 106, n. 6, p. 1955-1962, 2014. https://doi.org/doi:10.2134/agronj14.0277

GASPAR, A. P.; MITCHELL, P. D.; CONLEY, S. P. Economic risk and profitability of soybean fungicide and insecticide seed treatments at reduced seeding rates. Crop Science, v. 55, n. 2, p. 924-933, 2015. https://doi.org/10.2135/cropsci2014.02.0114

GEISER, M. S.; AOKI, T.; BACON, C. W.; BAKER, S. A.; BHATTACHARYYA, M. K. et al. A fungus, a name: defining the genus Fusarium in a scientifically robust way that preserves long-standing use. Fitopatologia, v. 103, p. 400-408, 2013. 10.1094/PHYTO07-12-0150-LE

GERAERT, E. The Pratylenchidae of the world: identification of the family Pratylenchidae (Nematoda: Tylenchida). Academia Press, 2013. 
GHINI, R.; ZARONI, M. M. Relação entre coberturas vegetais e supressividade de solos a Rhizoctonia solani. Fitopatologia Brasileira, v. 26, n.1, p. 10-15, 2001.

GUPTA, G. K.; SHARMA, S.K.; RAMTEKE, R. Biology, epidemiology and management of the pathogenic fungus Macrophomina phaseolina (Tassi) Goid with special reference to charcoal rot of soybean (Glycine max (L.) Merrill). Journal of phytopathology, v. 160, n. 4, p. 167-180, 2012. https://doi.org/10.1111/j.1439-0434.2012.01884.x

HENNING, A. A.; ALMEIDA, Á. M. R.; GODOY, C. V.; SEIXAS, C. D. S.; YORINORI, J. T.; COSTAMILAN, L. M.; DIAS, W. P. Manual de identificação de doenças de soja. Embrapa Soja-Documentos (INFOTECA-E). (2005).

HENNING, A. A.; COSTAVAL, W. N.; FRANÇA NETO, J. B.; KRYZANOWSKI, H. P.; COSTA, N. P.; ALVES, E. R. S.; COSTAMILAN, L.; ANDRADE, P. M.; GOULART, A. C. P.; VIEIRA, P. A.; FIEGEBAUM JR, V.; MAYER, S.; GARCIA, L. L. C.; PERES, A. S.. Fungicidas para o tratamento de soja. Informativo Abrates, v. 5, n. 2, p. 106, 1995.

HODDA, M. I. K. E., COLLINS, S. J., VANSTONE, V. A., HARTLEY, D. I. A. N. A., WANJURA, W. O. L. F. G. A. N. G. et al. Pratylenchus quasitereoides n. sp. from cereals in Western Australia.Zootaxa, v. 3866, n. 2, p. 277-288, 2014. http://dx.doi.org/10.11646/zootaxa.3866.2.6

HUANG, J., WEI, Z., TAN, S., MEI, X., YIN, S., et al. The rhizosphere soil of diseased tomato plants as a source for novel microorganisms to control bacterial wilt. Applied soil ecology, v. 72, p. 79-84, 2013. https://doi.org/10.1016/j.apsoil.2013.05.017

HÜBERLI, D.; HAYDEN, K. J.; CALVER, M.; GARBELOTTO, M. Intraspecific variation in host susceptibility and climatic factors mediate epidemics of sudden oak death in western US forests. Plant Pathology, v. 61, n. 3, p. 579-592, 2012. https://doi.org/10.1111/j.1365-3059.2011.02535.x

ISLAM, M. S.; HAQUE, M. S.; ISLAM, M. M.; EMDAD, E. M.; HALIM, A. et al. Ferramentas para matar: genoma de um dos fungos patogênicos mais destrutivos de plantas Macrophomina phaseolina. Bmc Genomics, v. 13, n. 1, p. 493, 2012. https://doi.org/10.1186/1471-2164-13-493

JABER, L. R.; ALANANBEH, K. M. Fungal entomopathogens as endophytes reduce several species of Fusarium causing crown and root rot in sweet pepper (Capsicum $\begin{array}{lllll}\text { annuum L.). Biological } & \text { Control, v. } & 126, & \text { p. } & 117-126,\end{array}$ https://doi.org/10.1016/j.biocontrol.2018.08.007

JOHNSON, D. A. Stability of slow-rusting resistance to Puccinia asparagi and managing rust in asparagus. Plant disease, v. 96, n. 7, p. 997-1000, 2012. https://doi.org/10.1094/PDIS-09-11-0797-RE 
JONES, J. B.; JONES, J. P.; STALL, R. E.; ZITTER, T. A. Compendium of tomato disease. Bradenton. 73 p. 1993.

KATAN, J.; GAMLIEL, A. Plant Health Management: Soil Solarization. Encyclopedia of Agriculture and Food Systems, p. 460-471, 2014. https://doi.org/10.1016/B978-0-44452512-3.00256-4

KLOSTERMAN, S. J.; SUBBARAO, K. V.; KANG, S. C.; VERONESE, P.; GOLD, S. $\mathrm{E}$. et al. Comparative genomics provides insight into the niche adaptation of vascular pathogens in plants. PLoS Pathogns, v. 7, n. 7, 2011. https://doi.org/10.1371/journal.ppat.1002137

LEMESSA, F.; ZELLER, W. Screening rhizobacteria for biological control of Ralstonia solanacearum in Ethiopia. Biological control, v. 42, n. 3, p. 336-344, 2007. https://doi.org/10.1016/j.biocontrol.2007.05.014

LYU, X. L.; SHEN, C. C.; FU, Y. P.; XIE, J. T. JIANG, D. H. et al. The sop1 opsine microbial counterpart is involved in Sclerotinia sclerotiorum development and response to environmental stress. Frente Microbiology, v. 6, p. 1504, 2016.

MAPA. Ministério da Agricultura Pecuária e Abastecimento - Agrofit. (2018). Disponível em: http://agrofit.agricultura.gov.br/agrofit_cons/principal_agrofit_cons. Acessado em 05/11/2018.

MARINO, R. H.; MESQUITA, J. B.; DE ANDRADE, K. V.; COSTA, N. A. D.; AMARAL, L. A. Incidência de fungos em sementes de Phaseolus vulgaris $L$. provenientes do Estado de Sergipe. Revista Brasileira de Ciências Agrárias, v. 3, n. 1, 2008.

MASSENSSINI, A. M.; BONDUKI, V. H. A.; MELO, C. A. D.; TÓTOLA, M. R.; FERREIRA, F. A. et al. Relative importance of soil physico-chemical characteristics and plant species identity to the determination of soil microbial community structure. Applied Soil Ecology, v. 91, p. 8-15, 2015. https://doi.org/10.1016/j.apsoil.2015.02.009

MCBRATNEY, A. B.; FIELD, D. J.; $\mathrm{KOCH}$, A. The dimensions of soil safety. Geoderma, v. 213, p. 203-213, 2014. https://doi.org/10.1016/j.geoderma.2013.08.013

MCGOVERN, R. J. Management of tomato diseases caused by Fusarium $\begin{array}{llllll}\text { oxysporum. Crop } & \text { Protection, } & \text { v. } & 73, & \text { p. }\end{array}$ https://doi.org/10.1016/j.cropro.2015.02.021

MENGISTU, A.; SMITH, J. R.; RAY, J. D.; BELLALOUI N. O progresso sazonal da podridão do carvão e seu impacto na produtividade da soja. Plant Disease, v. 95, n.9, p. 1159-1166, 2011. https://doi.org/10.1094/PDIS-02-11-0100

MICHEREFF, S. J.; ANDRADE, D. E. G. T.; PERUCH, L. A.; MENEZES, M. Importância dos patógenos e das doenças radiculares em solos tropicais. Ecologia e manejo de patógenos radiculares em solos tropicais, v. 1, p. 1-18, 2005. 
MIRANDA, B. E. C.; BOITEUX, L. S.; CRUZ, E. M.; REIS, A. Fontes de resistência em acessos de Solanum (secção Lycopersicon) a Verticillium dahliae raças 1 e 2 . Horticultura Brasileira, v. 28, p. 458-465, 2010.

MITCHUM, M. G. Soybean resistance to the soybean cyst nematode Heterodera glycines: an update. Phytopathology, v. 106, n. 12, p. 1444-1450, 2016. https://doi.org/10.1094/PHYTO-06-16-0227-RVW

MUELLER, D. S.; WISE, K. A.; SISSON, A. J.; ALLEN, T. W.; et al. Corn yield loss estimates due to diseases in the United States and Ontario, Canada from 2012 to 2015. Plant Health Progress. v. 17, n. 3, p. 211-222, 2016. https://doi.org/10.1094 / PHP-RS$16-0030$

MUNKVOLD, G. P.; WATRIN, C.; SCHELLER, M.; ZEUN, R.; OLAYA, G. Benefits of chemical seed treatments on crop yield and quality. In: Global perspectives on the health of seeds and plant propagation material. Springer, Dordrecht, 2014. p. 89103.

NASERI, B.; HAMADANI, S. A. Characteristic agro-ecological features of soil populations of bean root rot pathogens. Rhizosphere, v. 3, p. 203-208, 2017. https://doi.org/10.1016/j.rhisph.2017.05.005

NASERI, B.; HEMMATI, R. Bean root rot management: Recommendations based on an integrated approach for plant disease control. Rhizosphere, v. 4, p. 48-53, 2017. https://doi.org/10.1016/j.rhisph.2017.07.001

NASERI, B.; MOUSAVI, S. S. Root rot pathogens in field soil, roots and seeds in relation to common bean (Phaseolus vulgaris), disease and seed production. International journal of pest management, v. 61, n. 1, p. 60-67, 2015. https://doi.org/10.1080/09670874.2014.993001

NASERI, B.; SHOBEIRI, S. S.; TABANDE, L. The intensity of a bean Fusarium root rot epidemic is dependent on planting strategies. Journal of Phytopathology, v. 164, n. 3, p. 147-154, 2016. https://doi.org/10.1111/jph.12438

NECHET, K. L.; HALFELD-VIEIRA, B. A. Caracterização de isolados de Rhizoctonia spp., associados à mela do feijão-caupi (Vigna unguiculata), coletados em Roraima. Fitopatologia Brasileira, v. 3, n. 31, p. 505-508, 2006.

NICOL, J. M.; TURNER, S. J.; COYNE, D. L.; DEN NIJS, L.; HOCKLAND, S. Current Nematode Threats to World Agriculture. Genomics and Molecular Genetics of $\begin{array}{llll}\text { Plant-Nematode } & \text { Interactions, } & \text { p. } & 21-43 .\end{array}$ https://link.springer.com/chapter/10.1007\%2F978-94-007-0434-3_2

NYCZEPIR, A. P.; BECKER, J. O. Fruit and Citrus Trees. In: BARKER, K. R.; ENCICLOPÉDIA BIOSFERA, Centro Científico Conhecer - Goiânia, v.15 n.28; p.799 2018 
PEDERSON G. A.; WINDHAM, G. L. (eds). Plant and Nematodes Interactions. Madison: American Society of Agronomy, 1998. p. 637-684.

OKUBARA, P. A.; DICKMAN, M. B.; BLECHL, A. E. Molecular and genetic aspects of controlling the soilborne necrotrophic pathogens Rhizoctonia and Pythium. Plant Science, v. 228, p. 61-70, 2014. https://doi.org/10.1016/j.plantsci.2014.02.001

PALOMARES-RIUS, J. E.; CASTILLO, P.; LIÉBANAS, G.; VOVLAS, N.; LANDA, B. B. et al. Description of Pratylenchus hispaniensis n. sp. from Spain and considerations on the phylogenetic relationship among selected genera in the family Pratylenchidae. Nematology, v. 12, n. 3, p. 429-451, 2010. http://dx.doi.org/10.1163/138855409X12559479585043

PANABIERES, F.; ALI, G. S.; ALLAGUI, M. B.; DALIO, R. J.; GUDMESTAD, N. C. et al. Doenças de Phytophthora nicotianae no mundo: novos conhecimentos de um patógeno há muito reconhecido. Phytopathologia Mediterranea, v. 55, n. 1, p. 20-40, 2016. https://doi.org/110.14601/ Phytopathol_Mediterr-16423

PETERS, R. D.; PLATT, H. W.; LEZVES, C. A. Primeiro relato de Pythium sylvaticum causando podridão do tubérculo. Sou. J. Potato Res, v. 82, n.2, p. 173-177, 2005. https://link.springer.com/article/10.1007/BF02853655

PINHEIRO, J. B., DE CARVALHO, A. D. F., PEREIRA, R. B., RODRIGUES, C. D. S Nematóides na cultura do alho e cebola. Embrapa Hortaliças-Circular Técnica (INFOTECA-E), 2014.

POLAND, J. A.; BALINT-KURTI, P. J.; WISSER, R. J.; PRATT, R. C.; NELSON, R. J. Shades of gray: the world of quantitative disease resistance. Trends in plant science, v. 14, n. 1, p. 21-29, 2009. https://doi.org/10.1016/j.tplants.2008.10.006

PRATT, R. G. Uma técnica de observação direta para avaliar a germinação de escleródios por Macrophomina phaseolina e os efeitos de materiais de bio-controle na sobrevivência de escleródios no solo. Mycopathologia, v. 162, p. 121 -131, 2006.

PUNJA, Z. K. A The biology, ecology and control of Sclerotium rolfsii. Anual Review of Phytopathology, v. 23, n. 3, p. 97-127, 1985. https://doi.org/1985.23:97-127

REIS, E. M.; SANTOS, H. P. Interações entre doenças de cereais de inverno e sistema plantio direto. In: Embrapa-Fecotrigo e Fundação ABC. Plantio Direto no Brasil. Passo Fundo. 1983. p.105-110.

REIS, E.M.; CASA, R.T.; BIANCHIN, V. Controle de doenças de plantas pela rotação de culturas. Summa Phytopathologica, v. 37, n. 3, p. 85-91, 2011.

REYES-FRANCO, M. C.;HERNÁNDEZ-DELGADO, S.; BEAS-FERNÁNDEZ, R.; MEDINA-FERNÁNDEZ, M.; SIMPSON, J.; MAYEKPÉREZ, N. 
Pathogenic and genetic variability within Macrophomina phaseolina from Mexico and other countries. Journal of Phytopathology, v. 154, n. 7-8, p. 447-453, 2006.https://doi.org/10.1111/j.1439-0434.2006.01127.x

ROTEM, J.; PALTI, J. Epidemiological factors as related to plant disease control by cultural practices. In: PALTI, J.; KRANZ, J. (Eds.) Comparative Epidemiology: A Tool for Better Disease Management. Wageningen. Centre for Agricultural Publishing and Documentation. 1980. p.104-116.

SEINHORST, J. W. Population studies on stem nematodes (Ditylenchus dipsaci). Nematologica, v.1, n. 2, p. 159-164, 1956. https://doi.org/10.1163/187529256X00555

SIAMAK, S. B.; ZHENG, S. Banana Fusarium Wilt (Fusarium oxysporum f. sp. cubense) Control and Resistance, in the Context of Developing Wilt-resistant Bananas Within Sustainable Production Systems. Horticultural Plant Journal, v. 4, n. 5, p. 208-218, 2018. https://doi.org/10.1016/j.hpj.2018.08.001

SILVA, M. G.; SHARMA, R. D.; JUNQUEIRA, A. M. R.; OLIVEIRA, C. M. Efeito da solarização, adubação química e orgânica no controle de nematóides em alface sob cultivo protegido. Horticultura Brasileira, v. 24, p. 489-494, 2006.

SINGH, S. P.; SINGH, H. B.; SINGH, K. D. Biocontrol potential of mixture of trichoderma Isolates on damping-off and collar rot of tomato. The Bioscan, v. 9, n. 3, v. 3, p. 13011304, 2014.

SINGH, V. K.; NARESH, P.; BISWAS, S. K.; SINGH, G. P. Efficacy of fungicides for the management of wilted lentil disease caused by Fusarium oxysporum f.sp.lentis Annals of plant protection sciences, v. 18, n. 2, p. 411-414, 2010. http://www.indianjournals.com/ijor.aspx?target=ijor:apps\&type=home

SOWIK, I.; BORKOWSKA, B.; MARKIEWICZ, M. The activity of mycorrhizal symbiosis in suppressing Verticillium wilt in susceptible and tolerant strawberry (Fragaria $X$ ananassa Duch.) genotypes. Applied soil ecology, v. 101, p. 152-164, 2016. https://doi.org/10.1016/j.apsoil.2016.01.021

STIRLING, G. R. Integration of organic amendments, crop rotation, residue retention and minimal cultivation in a subtropical vegetable cultivation system increases suppression of the gill nematode (Meloidogyne incognita). Australasian Plant $\begin{array}{llllll}\text { Pathology, v. } & 42, & \text { n. } & 6, & \text { p. } & 625-637,\end{array}$ https://link.springer.com/article/10.1007/s13313-013-0236-9

SUN, G. Z.; YAO, T.; FENG, C. J.; CHEN, L.; LI, J. H.; et al. Identificação e potencial de biocontrole de bactérias antagonistas contra Sclerotinia sclerotiorume seus efeitos promotores de crescimento em Brassica napus. Biological Controle, v. 104, p. 3543, 2017. 
SUTTON, G. F.; COMPTON, S. G.; COETZEE, J. A. Naturally occurring phytopathogens enhance biological control of water hyacinth (Eichhornia crassipes) by Megamelus scutellaris (Hemiptera: Delphacidae), even in eutrophic water. Biological Control, v. 103, p. 261-268, 2016. https://doi.org/10.1016/ j.biocontrol.2016.10.003

TALAVERA, M.; SAYADI, S.; CHIROSA-RÍOS, M.; SALMERÓN, T.; FLORPEREGRÍN, E. et al. Perception of the impact of root-knot nematode-induced diseases in horticultural protected crops of southeastern. Spain Nematology, v. 14, n.5, p. 517527, 2012. https://doi.org/10.1163/156854112X635850

TAMM, L.; HÜRIG, B.; BRUNS, C.; FUCHS, J. G.; KÖPKE, U. et al. Soil type, history management, and soil changes influence soil development (Rhizoctonia solani, Pythium ultimum) and air (Phytophthora infestans, Diseases of Hyaloperonospora parasitica). European Journal of Plant Pathology, v. 127, p. 465-481, 2010. https://link.springer.com/article/10.1007\%2Fs10658-010-9612-2

VAN BRUGGEN, A. H. C.; FINCKH, M. Plant diseases and management approaches in organic farming systems. Annual Review of Phytopathology, v. 54, p. 25-54, 2016. https://doi.org/10.1146/annurev-phyto-080615-100123

VAN BRUGGEN, A. H. C.; SEMENOV, A. M. Soil Health and Soilborne Diseases in Organic Agriculture (Chapter 3.2). In: Finckh, M., van Bruggen, A.H.C., Tamm, L. (Eds.), Plant Diseases and Their Management in Organic Agriculture. APS Press, St. Paul, Minnesota, p. 67-89, 2015. https://doi.org/10.1094/9780890544785.007

VAN DEN BOSCH, F.; GILLIGAN, C. A. Medidas de durabilidade da resistência. Fitopatologia , v. 93, n. 5, p. 616-625, 2003.

VERDEJO-LUCAS, S.; CASTILLO, P. Nódulos en las raíces de tomate (Meloidogyne spp) (Eds.), Enfermedades causadas por nematodos fitoparásitos en España, Phytoma España y SEF. España, p. 143-154. 2011.

WANG, H., ZHUO, K., YE, W., \& LIAO, J. (2015). Morphological and molecular charaterisation of Pratylenchus parazeae n. sp.(Nematoda: Pratylenchidae) parasitizing sugarcane in China. European journal of plant pathology, v. 143, n. 1, p. 173-191, 2015. https://doi.org/10.1007/s13238-013-0009-9

WHEELER, T.; RUSH, C.M. Soilborne diseases. In: MALOY, O. C.; MURRAY, T. D. (Eds.) Encyclopedia of Plant Pathology. New York. JohnWiley \& Sons. 2001b. p. 935947.

WEILAND, J. E. Influence of the isolation method on the recovery of pythium species from forest nursery soil in oregon and Washington. Plant Disease, v. 95, n.5, p. 547553, 2011. https://doi.org/10.1094/PDIS-04-10-0242 
WHISSON, S. C.; BOEVINK, P. C.; WANG, S.; Birch, P. R. The cell biology of late blight disease. Current Opinion in Microbiology, v. 34, p. 127-135, 2016. https://doi.org/10.1016/j.mib.2016.09.002

ZAMBOLIM, L.; COSTA, H.; LOPES, C. A.; VALE, F. X. R. Doenças de hortaliças em cultivo protegido. Informe Agropecuário, v. 20, p. 114-125, 1999.

ZAMBOLIM, L.; VALE, F. X. R.; COSTA, H. Controle integrado das doenças de hortaliças. Viçosa: Universidade Federal de Viçosa. 1997.

ZHAO, P.; ZHAO, Y. L.; JIN, Y.; ZHANG, T.; GUO, H. S. Root colonization process of Arabidopsis thaliana by a fluorescent green protein labeled Verticillium dahliae isolate. Protein \& cell, v. 5, n. 2, p. 94-98, 2014. 